\title{
ENSINO DE LÍNGUAS POR MOBILE LEARNING: A EXPERIÊNCIA DE DESENVOLVIMENTO DO APLICATIVO VECINDARIO
}

\author{
SÃO PAULO/SP MAIO/2018 \\ Izabel Rego de Andrade - Senai-SP - izarego@gmail.com \\ Tipo: Investigação Científica (IC) \\ Natureza: Relatório Final de Pesquisa \\ Categoria: Métodos e Tecnologias \\ Setor Educacional: EDUCAÇÃO CONTINUADA EM GERAL
}

\begin{abstract}
RESUMO
O ensino de línguas assistido por dispositivos móveis (ALADIM) vem sendo disseminado em diversas partes do mundo como uma forma de estudo autônomo de línguas estrangeiras. A presente pesquisa é parte de uma investigação mais ampla que buscou analisar diferentes aplicativos educacionais com esse propósito para, a seguir, propor um aplicativo para a aprendizagem de espanhol como língua estrangeira, considerando princípios propostos para uma educação linguística contemporânea.

No presente artigo, descreve-se de que formas buscou-se aplicar os princípios teóricos estudados na elaboração do design educacional de um aplicativo, nomeado Vecindario, dedicado à aprendizagem da língua espanhola.

Tal investigação torna-se relevante no cenário em que os professores se veem diante da necessidade de se apropriar das tecnologias digitais para propor formas alternativas de uso de tais tecnologias com finalidades educativas que proporcionem experiências de aprendizagem significativas.
\end{abstract}

Palavras-chave: Mobile learning; Aprendizagem de Línguas; Mobile Assisted Language Learning

AGRADECIMENTOS

AGRADEÇO À PROFA. DRA. DENISE BÉRTOLI BRAGA E AO PROF. DR. RODOLFO AZEVEDO JARDIM PELA ORIENTAÇÃO E APOIO NA CONCRETIZAÇÃO DESSE PROJETO. 


\section{Introdução}

O presente artigo apresenta o processo de elaboração do design educacional de um aplicativo para aprendizagem da língua espanhola a partir de princípios conceituais de uma educação linguística contemporânea (ELC).

O trabalho é parte de uma pesquisa de doutorado mais ampla, na qual foram realizados dois estudos empíricos. No primeiro estudo, foram analisados aplicativos de ensino de espanhol como língua estrangeira, de modo a observar questões didáticas e linguísticas de cada aplicativo e identificar os aspectos críticos e desejáveis relacionados ao ensino de espanhol em uma proposta de aprendizagem de línguas assistida por dispositivos móveis (ALADIM).

No segundo estudo empírico, foi proposto o design de um aplicativo chamado Vecindario, voltado para aprendizagem de espanhol por mobile learning, ajustado ao contexto atual e às possibilidades que as tecnologias digitais permitem explorar. $\mathrm{Na}$ elaboração dessa proposta, a pesquisadora atuou como conteudista, definindo o currículo e escrevendo o conteúdo do curso e, também, como designer educacional - ou designer instrucional - ao elaborar o projeto didático e a roteirização do aplicativo.

\section{Fundamentação teórica}

No cenário atual, a educação linguística deve buscar atender às necessidades dos alunos e ser adequada ao contexto tecnológico em que a sociedade se insere. Isso se dá especialmente no mundo contemporâneo, no qual imagem, escrita, movimento e som se fundem em composições digitais multimodais trocadas com grande velocidade no meio virtual. Por essa razão, o ensino de línguas deve levar em consideração a semiótica, que estuda as formas de expressão que podem ser tomadas como signo, tais como palavras, imagens, sons, gestos, entre outros.

As tecnologias estão cada vez mais presentes em propostas pedagógicas de ensino de línguas, seja na modalidade presencial ou a distância, permitindo criar estratégias e usar recursos até então pouco acessíveis. Em especial, as tecnologias digitais móveis têm amplo uso na sociedade contemporânea, já que permitem portar, em um pequeno aparelho, ferramentas de edição de texto e imagem, geolocalizador, conexão com internet sem fio, armazenamento e reprodução de um grande volume de dados e comunicar-nos com outras pessoas em qualquer parte do mundo. Esses usos de dispositivos pessoais e portáteis "permitem novas formas de aprendizagem, enfatizando a continuidade ou espontaneidade do acesso e interação através de diferentes 
contextos de uso" (KUKULSKA-HULME, SHIELD, 2008, p. 273).

Partindo dessas considerações, na presente pesquisa, os aspectos considerados mais relevantes para se pensar em uma educação linguística contemporânea são os seguintes:

- Texto e contexto - O estudo das estruturas linguísticas deve focar na construção de sentido no texto (Halliday, 1978). Ao se ensinar uma língua considerando o texto como escopo maior do que palavras e expressões, é possível apresentar estratégias para o aluno aprender a fazer as previsões de sentido adequadas aos contextos sociais e culturais em que a comunicação ocorre.

- Multimodalidade - Pela semiótica, deve-se considerar outros modos de fazer sentido além do texto escrito, tais como: imagem, som, gestos, espaço, entre outros. No contexto atual, de fácil acesso aos recursos das tecnologias digitais, tais modos semióticos ganham mais destaque, sendo cada vez mais presentes na forma de expressão em meios digitais.

- Autonomia - É importante orientar os estudantes para usos das mídias digitais, disponíveis para a aprendizagem, já que estas permitem ter um controle mais autônomo sobre seu processo de aprendizagem de língua. A reflexão metacognitiva leva o aluno a desenvolver estratégias de controle dos processos cognitivos e de conhecimento analisado de língua (BRAGA, 2010), de modo que ele possa buscar formas de preencher lacunas no conhecimento prévio e sistematizar o conhecimento que está adquirindo.

- Motivação - A motivação envolve aspectos intrínsecos à pessoa e fatores extrínsecos, combinando o esforço ao desejo de alcançar a meta de aprendizagem (GARDNER, 1985). A motivação pode variar de uma pessoa para outra, transformando a aprendizagem em uma experiência pessoal e individual, ainda que tenha bases no contexto social em que o indivíduo se insere (MOURA, 2010).

- Ubiquidade - A ubiquidade favorece que o aluno utilize curtos momentos de tempo para aprender, independentemente de onde esteja, vivenciando o princípio de "aprender a qualquer hora e em qualquer lugar". Esse aspecto nem sempre se concretiza por questões relacionadas especialmente à disponibilidade de conexão com internet e às características das ferramentas de tecnologia dos dispositivos móveis (ZHANG, 2015).

Uma vez levantados os aspectos que devem compor o ensino de línguas no cenário contemporâneo, apresenta-se o desafio de transpor essas teorias para situações reais de ensino com uso de tecnologias digitais móveis. Tal situação é correntemente 
vivenciada por professores que se deparam com a necessidade de atualizar a sua prática docente com o uso das tecnologias digitais educacionais.

\section{Delineamento do aplicativo Vecindario}

Na presente pesquisa foi aplicada a metodologia de pesquisa estudo de caso, que "trata de uma investigação empírica que investiga um fenômeno contemporâneo dentro de seu contexto da vida real. Isso se dá especialmente quando os limites entre o fenômeno e o contexto não estão claramente definidos" (Yin, 2001). Na proposta deste estudo, o contexto compõe o objeto de estudo e ambas são relevantes para analisar o fenômeno em questão.

O projeto do aplicativo Vecindario, tem início com a tomada de decisão de selecionar o público-alvo a ser contemplado: estudantes de graduação de uma Universidade brasileira. A partir de tal definição, foi possível elaborar uma proposta de ensino contextualizado, considerando as vivências e o ambiente sociocultural em que tal público se situava.

A tomada de decisão seguinte se relaciona ao tipo de dispositivo móvel para o qual o aplicativo seria elaborado. Nesse caso, foi identificado que o público fazia largo uso de telefones celulares tipo smartphone com sistema operacional Android. $O$ fato de que existe uma ampla gama de aparelhos já não dificulta tanto o desenvolvimento técnico de aplicativos, uma vez que atualmente existe o design responsivo, que viabiliza a adaptação das telas projetadas para diferentes aparelhos.

Após tais definições, foi elaborado o currículo do curso, tomando como base os referenciais do Marco Comum Europeu de Referência (CERVANTES, 2002). Considerouse que um aprendiz brasileiro, com pouco ou nenhum conhecimento prévio na língua espanhola, seria capaz de adquirir habilidades dentro dos níveis A1 e A2 de proficiência. Após a seleção do currículo, elaborou-se um mapa de atividades, norteador para o desenvolvimento de um roteiro em formato de storyboard, composto por 83 telas que descrevem tecnica e pedagogicamente o aplicativo Vecindario.

\section{Estratégias pedagógicas e funcionalidades do aplicativo}

Os principais aspectos pedagógicos que nortearam a estruturação do aplicativo estão relacionados aos conceitos propostos para a educação linguística contemporânea e buscam conduzir o aprendiz pela experiência de aprendizagem, prevendo alguns percursos possíveis sem, no entanto, um engessamento. Os princípios norteadores 
estão relacionados a propor o engajamento, a interação social e a ubiquidade. Para tanto, foram traçadas as estratégias de gamificação, storytelling e modularização das atividades. A seguir descreve-se as algumas funcionalidades do aplicativo, bem como de que forma os princípios educacionais anteriormente apresentados foram transpostos para a proposta desse aplicativo.

\section{- Ranking}

O Ranking apresenta um quadro com a pontuação obtida por cada participante em relação ao grupo, mostrando o seu desempenho na realização das tarefas. Esse aspecto, relacionado à competição entre os participantes, pode ser motivador para que 0 aprendiz seja encorajado a superar o seu próprio desempenho e busque melhorar a sua pontuação. Para o docente, o Ranking permite diagnosticar a aprendizagem do grupo, identificando participantes com dificuldades em atividades específicas. Para o participante, estimula-o a seguir adiante para competir com o grupo e valoriza o seu esforço, por meio da condecoração com troféus e medalhas virtuais. No entanto, é sempre relevante observar como os participantes lidam com a competição, para que esta não se torne um fator gerador de ansiedade (CALLEGARI, 2008, p. 97).

\section{- Flashcard}

De modo a tornar a aprendizagem de vocabulário mais significativa, foi projetada uma ferramenta para o usuário criar os seus próprios cartões de memorização - ou flashcards - selecionando e organizando o novo léxico adquirido. O layout para criação de cada cartão digital permite ao aluno inserir: o vocabulário, um breve texto e uma imagem. Dessa forma, buscou-se desenvolver a percepção de como os textos multimodais podem ser construídos em língua estrangeira, ainda que em níveis iniciais de aprendizagem.

\section{- Charla}

Em geral, no estudo on-line, os estudantes buscam se comunicar por meio de ferramentas diversas, como salas de bate papo, grupos de e-mail e redes sociais. Essa formação de comunidades de apoio à aprendizagem se dá de forma independente quando esse espaço não está disponível na estrutura do ambiente em que acontece o curso. Portanto, para apoiar os participantes e promover a colaboração, o aplicativo traz o seu próprio espaço de conversa, denominado Charla, para que eles possam negociar sentidos em língua espanhola e se apoiar mutuamente na realização das tarefas. 


\section{- Tradução}

Todas as telas do aplicativo possuem um botão de tradução para a língua portuguesa. Essa função serve de apoio ao aprendiz que venha a ter dificuldades em compreender o texto apresentado em língua espanhola e para auxiliar na sistematização das novas expressões aprendidas. Tal recurso também favorece a autonomia, uma vez que permite que o aprendiz, por analogia entre os textos, traduza a expressão que desconhece.

\section{- Gamificação}

O uso de estratégias de jogos, conhecido como gamificação, em mobile learning auxilia a desenvolver a colaboração, a motivação, o letramento digital, a competição, entre outros aspectos. Ademais da motivação, a gamificação pode promover a autonomia do aprendiz, levando-o a tomar decisões e se apropriar das ferramentas para produzir informação e não apenas consumi-la (GEE, 2008), além de promover a colaboração entre participantes. A estrutura de gamificação para o aplicativo Vecindario inclui: pontuações em atividades didáticas; troféu virtual para premiar o participante que acertar todos os exercícios de um tópico; mecanismo de ajuda para o participante pedir ajuda para outros que já fizeram aquela atividade.

\section{- Modularização}

A organização do conteúdo do Vecindario foi pensada para favorecer a situação de ubiquidade: cada módulo é subdividido em tópicos curtos e independentes, que podem ser realizados em até 15 minutos (conforme sugerido por Kukulska-Hume, 2012). Os tópicos foram nomeados de forma diferente da lógica convencional de apresentação de tópicos gramaticais e foram organizados aleatoriamente. A proposta dessa organização não linear buscou dar autonomia ao participante para decidir o seu percurso de aprendizagem.

\section{- Sepa más}

Além dos tópicos de conteúdo, cada módulo conta com o espaço Sepa más, que apresenta informações complementares aos temas tratados. O objetivo está em apresentar possibilidades de acesso ao conhecimento que extrapolem os limites do aplicativo. Assim, o participante que desejar aprofundar os seus conhecimentos em um aspecto específico, tem um caminho para começar a sua exploração pela internet. As informações apresentadas nesse espaço são formatadas em pequenos textos e trazem 
links para vídeos e sites diversos.

\section{- Storytelling}

Utilizou-se storytelling - ou narrativa - de modo a proporcionar um contexto significativo para a aprendizagem, fazendo a conexão entre o conteúdo teórico abordado (funções, gramática, vocabulário etc) e a situação real de uso da língua. O storytelling, também, favorece a construção de empatia, permitindo que o participante se identifique com o personagem e com as situações vivenciadas por ele. Para apresentar ao público-alvo a língua espanhola, buscou-se no contexto sociocultural de estudantes universitários brasileiros, pessoas que vêm de países de língua espanhola para estudar no Brasil e passam por determinadas situações para se adaptar à rotina no país e na universidade.

Para aproximar esse contexto à realidade dos estudantes brasileiros, foram gravados vídeos com entrevistas com quatro estudantes de diferentes nacionalidades - México, Peru, Equador e Bolívia, relatando as suas experiências de chegada ao nosso país e de adaptação ao novo ambiente universitário. As situações narradas pelos estudantes foram o pano de fundo para elaborar atividades de aprendizagem que levaram o aprendiz brasileiro a compreender a fala desses estrangeiros e expressar-se, de forma oral ou escrita, em situações similares. As narrativas relacionadas à vivência do estudante ajudam a criar uma comunicação em um contexto significativo.

\section{Atividades didáticas do aplicativo}

A seguir serão apresentados dois tópicos do módulo 1: Sopa de letras e La palabra. Dessa forma, deseja-se mostrar como o design educacional proposto relacionou os princípios pedagógicos de ELC com a experiência de aprendizagem pelo aplicativo.

\section{Sopa de letras}

Considerando que o público-alvo não estudou a língua espanhola formalmente em outras situações e considerando a proximidade com a língua materna dos participantes, essa atividade buscou apresentar o alfabeto sob uma perspectiva contrastiva, destacando as diferenças fonéticas e ortográficas entre português e espanhol. Para tanto, foi selecionado léxico de conhecimento geral do público brasileiro, inclusive com falsos cognatos e topônimos, buscando favorecer a percepção do participante de que, mesmo sem ter estudado a língua previamente, conseguirá compreender algumas expressões. 
Essas expressões foram apresentadas em uma nuvem de palavras para que o aluno toque em cada palavra alternadamente. Cada palavra dá acesso a uma nova tela com as seguintes informações:

- Grafia e áudio da palavra selecionada (com a sua pronúncia em espanhol);

- Explicação das diferenças e semelhanças fonéticas entre tal letra e a sua correspondente em português; e

- Outros exemplos de palavras com a mesma letra, acompanhados de áudio com a pronúncia.

Essa atividade é interativa, mas não foi proposta uma pontuação para a sua realização, já que a intenção estava centrada na sensibilização do participante para a língua a ser estudada.

\section{La palabra}

O tópico apresenta os artigos definidos em situações de uso da língua. Foi organizado em duas sessões principais: a primeira sessão com o conteúdo teórico e a segunda sessão com exercícios relacionados aos conceitos estudados. Inicialmente foi apresentado um vídeo com trecho da entrevista aos estudantes hispanofalantes narrando porque decidiram vir ao Brasil estudar na Universidade em questão. A seguir, um texto dá destaque a trechos do vídeo com diferentes usos dos artigos definidos, seguido de algumas telas com textos e áudios referentes ao mesmo assunto. Na sessão seguinte, foram apresentados dois exercícios para sistematização do conhecimento.

As demais atividades didáticas propostas compõem um crescendo de complexidade em termos de uso da língua espanhola. O storyboard apresentado foi utilizado para realizar o desenvolvimento técnico de um protótipo do aplicativo. Foi realizada uma parceria com pesquisadores do instituto de computação da Universidade para a concretização do aplicativo Vecindario. Do trabalho conjunto dessa equipe, surgiu o protótipo do módulo 1 do aplicativo Vecindario - publicado e disponível atualmente na loja de aplicativos Google Play. O protótipo foi validado com participantes voluntários que permitiram levantar aspectos técnicos, pedagógicos e de design que poderão ser aprimorados para as etapas seguintes de desenvolvimento do aplicativo.

\section{Considerações finais}

Pelo estudo empírico apresentado nesse artigo, o processo de criação de um aplicativo para ensino de línguas requer a mobilização de capacidades de diferentes naturezas: 
por um lado, requer compreender as possibilidades e limitações técnicas de se utilizar dispositivos móveis para promover esse tipo de ensino; por outro, requer levantar as perdas e ganhos pela perspectiva pedagógica. Reunir ambas percepções demanda 0 envolvimento de equipes multidisciplinares, buscando estabelecer pontes entre os processos criativos e técnicos. Em especial, destaca-se os ganhos para um professor de línguas estrangeiras que se disponha a passar pelo processo de criar um aplicativo, já que esse processo favorece reflexões sobre os processos de ensinar e aprender e sobre como as tecnologias digitais móveis podem contribuir para o sucesso da aprendizagem.

\section{Referências}

ANDRADE, I. A. Aprendizagem de língua assistida por dispositivos móveis (ALADIM): uma proposta alternativa para 0 ensino da língua espanhola. Tese (doutorado) - Universidade Estadual de Campinas, Instituto de Estudos da Linguagem. 2017. 343p.

BRAGA, D. B. Aprendizagem reflexiva de leitura em língua estrangeira: Questões relativas à construção de materiais digitais para acesso independente, Cáceres: Revista Latinoamericana de Tecnología Educativa, v.9, n.2, 2010. p. 6376.

CALLEGARI, M. V. Motivação e ensino de espanhol na escola pública paulista: dados quantitativos e qualitativos de um estudo de caso. Trabalhos em Linguística Aplicada, Campinas, n. 51, v.1, p. 99-117, jan./jun. 2008.

CERVANTES, I. Marco común europeo de referencia para las lenguas: aprendizaje, enseñanza, evaluación, 2002. Disponível em: $<$ http://cvc.cervantes.es/ensenanza/biblioteca_ele/marco/cvc_mer.pdf> Acesso em: 21 mar. 2017.

GARDNER, R.C. Social Psychology and Second Language Learning: The Role of Attitudes and Motivation. London: Edward Arnold, 1985. 208 p.

GEE, J.P. Social Linguistics and Literacies: Ideology in discourses. 3.ed. New York: Routledge, 2008, $248 \mathrm{p}$.

HALLIDAY, M. A. K. Language as Social Semiotic. London: Edward Arnold, 1978. 256 p.

KUKULSKA-HULME, A. Language learning defined by time and place: a framework for 
next generation design. In: DÍAZ-VERA, J. E. (ed.) Left to my own devices: learner autonomy and mobile assisted language learning. Bingley: Emerald, 2012. p. 3-20.

KUKULSKA-HULME, A.; SHIELD, L. An overview of mobile assisted language learning: From content delivery to supported collaboration and interaction. New York: ReCALL, v. 20, n. 3, 2008. p. 271-289.

MOURA, A. M. C. Apropriação do Telemóvel como Ferramenta de Mediação em Mobile learning: Estudos de Caso em Contexto Educativo. 2010. 630 p. Tese (doutorado) - Universidade do Minho, Braga, 2010.

YIN, R. K. Estudo de caso: planejamento e métodos. 2. ed. Porto Alegre: Bookman, 2001. $205 \mathrm{p}$.

ZHANG, Yu Aimee. (coord.). Handbook of mobile teaching and learning. Berlln: Springer, 2015. 1021p. 